\title{
Infographics, podcasts, and blogs: a multi-channel, asynchronous, digital faculty experience to improve clinical teaching (MAX FacDev)
}

\author{
Krista Dowhos ${ }^{1}$ Jonathan Sherbino ${ }^{2} \cdot$ Teresa M. Chan $^{2} \cdot$ Alim Nagji $^{1}$
}

Received: 1 May 2020 / Accepted: 15 December 2020 / Published online: 31 March 2021

(C) The Author(s), under exclusive licence to Canadian Association of Emergency Physicians (CAEP)/ Association Canadienne de Médecine d'Urgence (ACMU) 2021

\begin{abstract}
Attendance at faculty development events are often limited to those with time and interest, but all clinical teachers should have access to continuing faculty development. A multi-channel, asynchronous, digital faculty experience strategy (MAX FacDev) was used to engage busy emergency medicine (EM) teachers associated with a distributed medical education network involving ten geographically distinct teaching sites. An evidence-informed education bundle on key principles for clinical teaching was developed. The education bundle included five topics, serialized via: an infographic series posted in distributed medical education EM departments, a podcast series and a blog. The target audience included 102 faculty members and 46 residents. Within 8 months of launching MAX FacDev, there were 1508 podcast listens and 7686 pageviews. An education bundle can efficiently deliver on-demand faculty development. Amplifying key messages via multiple channels increases the reach of faculty development and reinforces the messages.
\end{abstract}

Keywords Continuing professional development $\cdot$ Emergency medicine $\cdot$ Podcasts $\cdot$ Blogs

\section{Résumé}

La participation aux activités de perfectionnement du corps professoral est souvent limitée à ceux qui ont du temps et de l'intérêt, mais tous les enseignants cliniciens devraient avoir accès au perfectionnement continu du corps professoral. Une stratégie multicanale, asynchrone et numérique de l'expérience du corps enseignant (MAX FacDev) a été utilisée pour engager des enseignants de la médecine d'urgence (MU) occupés, associés à un réseau d'éducation médicale régionalisée (EMR) impliquant 10 sites d'enseignement géographiquement distincts. Un ensemble de formation factuelle sur les principes fondamentaux de l'enseignement clinique a été élaboré. L'ensemble pédagogique comprenait cinq sujets, sérialisés via: une série d'infographie publiée dans les départements EMR et MU, une série de podcasts et un blog. Le public cible comprenait 102 membres du corps professoral et 46 résidents. Dans les 8 mois qui ont suivi le lancement de MAX FacDev, 1508 podcasts ont été écoutés et 7686 pages ont été consultées. Un ensemble pédagogique peut fournir efficacement la formation professorale à la demande. Accentuer les messages clés via plusieurs canaux augmente la portée du développement du corps professoral et renforce les messages.

Alim Nagji

anagji@gmail.com

Krista Dowhos

krista.dowhos@medportal.ca

Jonathan Sherbino

sherbino@mcmaster.ca

Teresa M. Chan

teresa.chan@medportal.ca
1 Division of Emergency Medicine, Department of Family Medicine, McMaster University, Hamilton, ON, Canada

2 Division of Emergency Medicine, Department of Medicine, McMaster Education Research Innovation and Theory (MERIT) Program, McMaster University, Hamilton, ON, Canada 


\section{Background}

Faculty development is a longitudinal, goal-directed process focusing on academic career growth [1]. With the shift to competency-based medical education, the importance of clinical teaching is emphasized with increasing attention to supervision, and direct observation with feedback [2]. Emergency medicine (EM) clinicians face challenging scheduling logistics for conventional faculty development initiatives such as in-person workshops. Moreover, with the recent COVID-19 pandemic, it has become abundantly clear that in-person events may not always be possible. Finally, our challenge is magnified in distributed medical education systems where community-based physicians have reduced access to central resources and are being asked to increasingly supervise trainees [3]. To combat this, we describe a novel multi-channel, asynchronous digital faculty development (MAX FacDev) initiative using infographics, podcasts, and blogs for on-demand faculty development.

\section{Rationale}

Key features of faculty development include longitudinal design, intentional community building, educationally informed and experiential learning [1]. The rationale for MAX FacDev was to provide evidence-informed clinical teaching strategies to all teachers in our catchment, including our distributed medical education faculty. Given the wide geographical footprint (our teaching network spans 13 hospitals and multiple communities, serving roughly 2 million people) and unsynchronized clinical and academic schedules within our distributed medical education system, it has been difficult to convene EM educators for traditional in-person faculty development workshops. The use of asynchronous engagement allows for flexibility in uptake and review in a longitudinal manner. Creating resources that can be accessed via multiple platforms allows for on-demand learning in an experiential manner.

\section{Description of innovation}

Digital resources including podcasts and blogs are a new normal for learning in emergency medicine and are a key source of clinical updates [4, 5]. Increasingly, infographics are commonplace in academic medicine with many journals using infographics to highlight key studies [6]. When compared to text-only summaries of medical literature, infographic representations have been shown to decrease cognitive load, increase abstract views, and tend to be a preferred method of reviewing medical literature; however, retention is poor [6].

Three clinician educators met to discuss local needs and developed an evidence-informed infographic series that covered key principles in clinical teaching: establishing learner expectations, using a teaching framework (the 1-min preceptor [7]), tagging and tailoring key teaching moments, delivering clear feedback, and assessing entrustable professional activities, and diagnosing your learner. Topics were chosen by expert consensus. The infographics were posted in ten distributed medical education teaching hospitals.

A podcast was developed to connect clinician teachers across the distributed medical education system and to highlight local initiatives and experts. The infographic topics were serialized and expanded via a podcast (MacEmerg Podcast https://sites.google.com/medportal.ca/macemerg$\mathrm{cpd} /$ podcast). Finally, the infographics were distributed via a series of posts on the CanadiEM blog [8] (http://bit. lyCJEM-BERappendixB).

\section{Outcomes: engagement data}

\section{Setting}

The local target audience included 102 faculty members and 46 residents, but the content was also suitable to a larger global audience.

\section{Dissemination strategies}

We have created a total of six blog posts on CanadiEM and a complimentary set of six MacEmerg Podcasts. For context, the CanadiEM website was founded in 2016 and receives an average of 2 million pageviews per year [8, 10]. The MacEmerg podcast was founded in 2019 and receives around 3000 listens per year.

\section{Analytics}

For the CanadiEM blog posts, we extracted data from the Google Analytics platform for each of the six individual blog posts in the Teaching that Counts series. We extracted these metrics: total pageviews from website, pageviews from cities/towns near McMaster, total unique visitors, unique visitors from cities/towns near McMaster, total number of cities/towns reached, and number of cities/towns near McMaster. We used these metrics to calculate the projected percentages of Pageviews, Unique visitors, and Cities/Towns from the McMaster area. The McMaster area was defined as any jurisdiction in which 
McMaster trainees or faculty work. For the MacEmerg podcast episodes, we extracted data from the Soundcloud platform for the six podcasts in the series.

\section{Results}

The infographics have been accessed on the CanadiEM blog 7686 times, with 784 of those originating from McMaster-affiliated cities/towns (Fig. 1). On average, each infographic blog post was visited by 328 unique Internet protocol (IP) addresses, with an average of $8.2 \%$ visits from McMaster-affiliated cities/towns.

The podcast episodes received 1508 listens with 656 of those listens originating from McMaster-affiliated cities/ towns. The average number of listens per episode was 223 (SD 87.3) with an average of 53\% (SD 9.4\%) originating from McMaster-affiliated cities/towns.

\section{Discussion}

We describe a novel educational bundle of integrated infographics, podcasts, and blogs to reach busy and geographically disparate EM teachers at distributed medical education sites. Engagement with the material suggests a demand for these resources and a need for translation of evidence-informed clinical teaching principles to the bedside. Previous literature has shown promise that podcasts may be useful as faculty development [9] and open access resources are popular with trainees who will then transition to junior faculty [10]. Bundling podcasts with infographics and blog posts may also be a useful and novel method for educators to amplify teaching.

This innovation has several limitations. First, engagement does not equate with learning or application of knowledge, so we have no way of knowing if clinical teaching was improved. Future studies could examine this. Second, we lack a control comparison to our current MAX FacDev bundle, since before this project, our region had no unified faculty development strategy, relying on a central, ad hoc workshop-based sessions that rarely addressed clinical teaching. Third, web-based analytics may be an imprecise method to determine access location, since many users mask their IP addresses, which prevents our inclusion of their data for determining sitebased metrics. Fourth, as production costs and technical hurdles have dramatically decreased, the podcast and blog market is increasingly becoming saturated [2]. Garnering attention in a crowded market is challenging. The local, tailored approach of MAD FacDev helps it to stand out, but popular EM podcasts and blogs compete for the attention of the target audience.
Fig. 1 An infographic depicting some of the key uptake outcomes for the Teaching that Counts MAX FacDev intervention

\section{Teaching that Counts
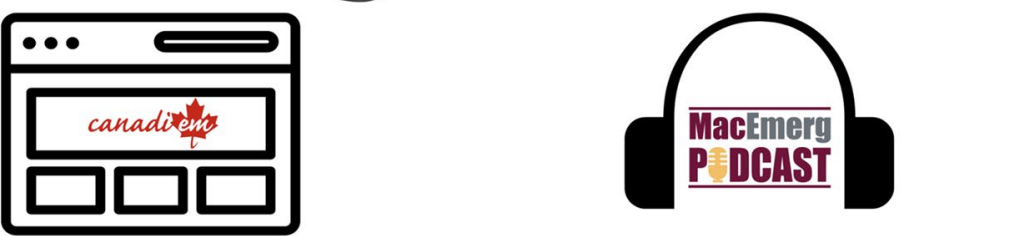

Total CanadiEM Pageviews 7,686 Pageviews

Average Pageviews per post $1,281(+\mid-660)$

Average percentage of Pageviews from local University-affiliated cities/towns

$9.1 \%(+/-7.4 \%)$
Total MacEmerg podcast listens $\mathbf{1 , 5 0 8 ~ l i s t e n s ~}$

Average listens per episode $233.0(+/-87.3)$

Average percentage of listens from local University-affiliated cities/towns $53.0 \%(+1-9.4 \%)$ 


\section{Conclusion}

An educational bundle of infographics, podcasts, and blog posts can efficiently deliver key educational messages for ondemand faculty development. Future study should determine the learning effectiveness of a multi-channel asynchronous on-demand faculty development process compared with traditional in-person offerings.

\section{Compliance with ethical standards}

Conflict of interest TC reports intellectual conflicts from MacEmerg Podcast, personal fees from McMaster Program for Faculty Development, during the conduct of the study; personal fees from ALiEM, LLC, outside the submitted work. AN reports personal fees from McMaster University, during the conduct of the study; personal fees from McMaster University, outside the submitted work. The remaining authors declare no conflict of interest.

\section{References}

1. Steinert Y, Mann K, Anderson B, et al. A systematic review of faculty development initiatives designed to enhance teaching effectiveness: a 10-year update: BEME Guide No. 40. Med Teach. 2016;38(8):769-86. https://doi.org/10.1080/0142159x. 2016.1181851 .

2. Sherbino J, Bandiera G, Doyle K, et al. The competency-based medical education evolution of Canadian emergency medicine specialist training. Can J Emerg Med. 2020;22(195-102):1-8. https://doi.org/10.1017/cem.2019.417.
3. Zelek B, Goertzen J. A model for faculty engagement in distributed medical education: crafting a paddle. Can Med Educ J. 2018;9(1):e68-73.

4. Chan TM, Stehman C, Gottlieb M, Thoma B. A short history of free open access medical education. The past, present, and future. ATS Scholar. 2020;1(2); 87-100. https://doi.org/10.34197/atsscholar.2020-0014ps.

5. Cadogan M, Thoma B, Chan TM, Lin M. Free Open Access Meducation (FOAM): the rise of emergency medicine and critical care blogs and podcasts (2002-2013). Emerg Med J. 2014;31(e1):e767. https://doi.org/10.1136/emermed-2013-203502.

6. Huang S, Martin LJ, Yeh $\mathrm{CH}$, et al. The effect of an infographic promotion on research dissemination and readership: a randomized controlled trial. Can J Emerg Med. 2018;20(6):826-33. https://doi.org/10.1017/cem.2018.436.

7. Neher JO, Gordon KC, Meyer B, Stevens N. A five-step "microskills" model of clinical teaching. J Am Board Fam Pract. 1992;5(4):419-24.

8. Ting DK, Thoma B, Luckett-Gatopoulos S, et al. CanadiEM: accessing a virtual community of practice to create a Canadian National Medical Education Institution. AEM Educ Train. 2019;3(1):86-91. https://doi.org/10.1002/aet2. 10199.

9. Bernstein J, Mazotti L, Ziv TA, Drowos J, Whitlock S, Wood SK, Galvin SL, Latessa R. Texting brief podcasts to deliver faculty development to community-based preceptors in longitudinal integrated clerkships. MedEdPORTAL. 2018;14. https://doi.org/10. 15766/mep_2374-8265.10755.

10. Purdy E, Thoma B, Bednarczyk J, Migneault D, Sherbino J. The use of free online educational resources by Canadian emergency medicine residents and program directors. CJEM. 2015;1717(22):101-6. https://doi.org/10.1017/cem. 2014.73. 